\title{
Autolysis of bovine skin, its endogenous proteases, protease inhibitors and their effects on quality characteristics of extracted gelatin
}

\begin{abstract}
The autolysis of pretreated bovine skin (PBS) (treated with $0.1 \mathrm{M} \mathrm{NaOH}$ and $1 \% \mathrm{HCl}$ ), its endogenous proteases, inhibitors and their effects on quality attributes of gelatin were examined. PBS was subjected to different temperatures $\left(20-90^{\circ} \mathrm{C}\right)$ and $\mathrm{pH}(2-9)$ and treated with different protease inhibitors. Maximum autolytic activity of PBS was observed at $40{ }^{\circ} \mathrm{C}$ and pH 5. Ethylene-bis (oxyethylenenitrilo) tetraacetic acid (EGTA) was the most effective in impeding the degradation of $\gamma-\beta$ - and $\alpha$ - chains of PBS protein indicating that metallocollagenases were the predominant endogenous proteases in bovine skin. Gelatin was extracted in the absence (GAE) and presence (GPE) of EGTA, and EGTA with papain enzyme (GPEP). GPEP had a higher yield and lower gel strength than GEA and GPE. Metallocollagenases partook in the degradation of gelatin thereby affecting its functional properties. Pretreating PBS with or without EGTA, and papain influenced the quality attributes of gelatin.
\end{abstract}

Keyword: Autolysis; Bovine skin; Endogenous proteases; Protease inhibitors; Metallocollagenases; Gelatin; Papain 